\title{
Immunoglobulin classes and liver function tests in Nigerian petrol attendants
}

\begin{abstract}
Prolonged exposure to petrol has been shown to be a significant health hazard, especially for skeletal, circulatory, immune and reproductive systems. The present study investigates liver functions (alanine amino transferase and aspartate amino transferase, alkaline phosphatase (ALP), total bilirubin, total protein and albumin) and immune functions ( $\lg , \lg A$ and $\lg M)$ in 29 male petrol attendants and compares them with corresponding values in 22 sex- and age-matched controls using spectrophotometry and single radial immunodiffusion method respectively for determining the functions. All the liver function tests were similar in both petrol attendants and the controls except for significantly lower levels of $\operatorname{ALP}(P=0.02)$. Also, the levels of $\lg G$ and $\lg A$ were similar in petrol attendants when compared with corresponding levels in controls, while the levels of IgM were significantly raised in petrol attendants when compared with corresponding levels in controls $(P=0.02)$. This study shows that parameters of liver functions are within normal range in Nigerian petrol attendants.
\end{abstract}

Key words: Bilirubin, immunoglobulin, liver enzymes, Nigeria, petrol

\section{INTRODUCTION}

Petrol (or gasoline) is a volatile and inflammable petroleumderived liquid mixture primarily used for internal combustion of engines. It consists of hydrocarbons (aromatic, saturated and unsaturated) and non-hydrocarbons $\left(\mathrm{N}, \mathrm{S}, \mathrm{O}_{2}\right.$, vanadium and nickel). ${ }^{[1,2]}$

The volatile nature of petrol makes it readily available in the atmosphere any time it is dispensed, especially at petrol filling stations and depots. People are exposed to gasoline fumes during fuelling and refuelling at gas stations, but the gas station attendants are more at risk by virtue of their occupational exposure. ${ }^{[2]}$ Atmospheric concentration of gasoline vapor (approximately $2000 \mathrm{ppm}$ ) is not safe when inhaled even for a brief period of time (seconds). During fuelling of vehicles, the concentration of gasoline vapor in the air is between 20 and 200 ppm. ${ }^{[2,3]}$ This amount is higher when there is a long queue of cars to be fuelled, which is a usual occurrence during fuel scarcity.

Components of car-exhaust as a result of internal combustion of petrol, which are harmful, are $\mathrm{CO}_{2^{\prime}}$ $\mathrm{NO}_{2^{\prime}} \mathrm{SO}_{2^{\prime}}$ benzene, formaldehyde and polycyclic hydrocarbons. These substances are known to produce harmful effects on the blood, bone marrow, respiratory system, lymph nodes, pregnancy and pregnancy outcomes. They also interact with the immune system to cause local and systemic responses ranging from overactive immune responses to immunosuppresion. ${ }^{[4,5]}$

Previous in vitro and animal studies on the effects of individual synthetic components of petrol reported increased incidence, severity and duration of respiratory infections, ${ }^{[6]}$ thus suggesting altered immune responses. Studies on immune responses in Nigerians were concentrated on those exposed to infectious agents or heavy metals, neglecting those working in petrol industries.

Our study determined the levels of immunoglobulin classes (IgG, IgA and IgM), liver enzymes (alanine amino transferase (ALT), alkaline phosphatase (ALP) and aspartate amino transferase (AST)), total bilirubin, total protein and albumin in 29 petrol attendants working in petrolfilling stations and compared them with corresponding levels in 22 sexand-age-matched controls. This is to determine the status of an aspect of specific humoral immunity and
O. M. Akinosun, O. G. Arinola, L. S. Salimonu Departments of Chemical Pathology and Immunology, College of Medicine, University of Ibadan, Nigeria

For correspondence: O. G. Arinola, Department of Chemical Pathology and Immunology, College of Medicine, University of Ibadan, Nigeria.

E-mail: arinolaog@doctor.com

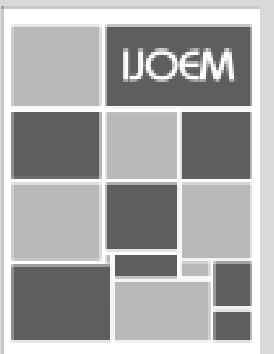


possible effects on liver integrity/functions in Nigerians exposed to petrol.

\section{MATERIALS AND METHODS}

Before the commencement of the study, ethical approval was obtained from UCH/UI Ethical Review Committee. A total of 51 Nigerian males (aged between 20 and 40 years) were studied. Among these were 29 male petrol attendants from Ibadan Metropolis, Nigeria; and 22 sex-and age-marched controls, which were selected from the staff of University College Hospital, Ibadan, Nigeria.

Determination of immunoglobulin classes, liver enzymes, total bilirubin, total protein and albumin.

Five (5) milliliters of venous blood was withdrawn from each subject, put into bottle containing lithium heparin and spun at 3,000 rpm for $5 \mathrm{~min}$ to obtain plasma. Serum concentrations of immunoglobulin classes (IgG, IgA and IgM) were estimated using single radial immunodiffusion method, ${ }^{[7]}$ while total protein, albumin, total bilirubin, ALT, AST and ALP were determined using Beckman's autoanalyser. ${ }^{[8]}$

\section{Statistical analysis}

Statistical analysis was performed by calculating the mean standard deviation and by Students $t$ test.

\section{RESULTS}

Table 1 presents the values of immunoglobulin classes in petrol attendants compared to corresponding values in controls. It shows that the mean levels of IgG and IgA were not significantly different in petrol attendants when compared with corresponding values in controls. IgM was significantly raised in petrol attendants when compared with corresponding values in controls $(P=0.02)$.

Table 2 compares the mean levels of total protein, albumin, ALT, AST, ALP and total bilirubin in petrol attendants with corresponding levels in controls. The mean values of ALP in

\section{Table 1: Mean \pm SD of immunoglobulin classes in petrol attendants and controls}

\begin{tabular}{lcccc}
\hline & $\mathbf{n}$ & $\lg \mathbf{G}(\mathbf{m g} / \mathbf{d L})$ & $\lg \mathbf{A}(\mathbf{m g} / \mathbf{d L})$ & $\mathbf{I g} \mathbf{M}(\mathbf{m g} / \mathbf{d L})$ \\
\hline Controls & 22 & $3510 \pm 1601$ & $163 \pm 56$ & $134 \pm 42$ \\
Attendants & 29 & $3438 \pm 1345$ & $179 \pm 66$ & $146 \pm 39$ \\
$\mathrm{t}, P$-values & & $0.17,0.9$ & $0.96,0.7$ & $2.25,0.02$ \\
\hline
\end{tabular}

petrol attendants were significantly lower than the corresponding values in the control group $(P=0.02)$. There were no significant differences in the mean values of total protein, albumin, alanine amino transferase and aspartate amino transferase and total bilirubin in petrol attendants when compared with corresponding values in controls.

\section{DISCUSSION}

Recognition that occupational and environmental agents can impair the functions of immune system and other organs has led to progress in further researches. This assertion is based on the previous studies on adverse effects of xenobiotics on organs and tissues in experimental animals and few humans. Studies on experimental animals and humans have shown that many experimental chemicals suppress the immune response, leading to increased incidence of influenza and common cold. ${ }^{[4,5]}$ Reports on the assessment of immunotoxicity in humans exposed to various agents as part of occupational exposure are relatively scarce. Apart from various routine toxicological evaluations that provide information on sequence of reactions leading to pathogenesis, there is also a need for biological markers to detect early stage of disease due to occupational exposure to the agents. The present study assessed the effect of petrol fume that is constantly inhaled by petrol attendants on liver functions and on an aspect of specific humoral immunity.

Liver is an important internal organ because it detoxifies the body from many toxins and synthesis range of proteins. Liver function tests (LFTs) are groups of clinical biochemistry laboratory blood assays that give information about the state of the liver. Most liver diseases cause only mild symptoms initially; therefore, it is vital that these diseases are detected early. The regular panels of LFTs are estimation of total protein (TP), albumin (Alb), (ALT), (ALP), total bilirubin (Tbil), (AST), gamma glutamyl transpeptidase and coagulase tests. ${ }^{[8,9]}$

TP and Alb were slightly raised in petrol attendants (though within the normal reference ranges, 6.0-8.0 g/dl and 3.0-5.0 $\mathrm{g} / \mathrm{dl}$ respectively). The liver produces most of the plasma proteins in the body, and albumin is a protein made specifically by the liver.

Estimation of TP may be of little clinical importance due to compensation between albumin and globulin fraction. Albumin (with half-life of approximately 20 days) is decreased in chronic liver disease, nephritic syndrome, a state of poor

Table 2: Parameters of liver functions in petrol attendants compared with controls

\begin{tabular}{lccccccc}
\hline & $\mathbf{n}$ & Total protein (g/dL) & Albumin (g/dL) & ALP (IU/L) & ALT (IU/L) & AST (IU/L) & Total bilirubin (mg/dL) \\
\hline Controls & 22 & $7.65 \pm 2.5$ & $5.03 \pm 0.4$ & $151 \pm 52$ & $53 \pm 11$ & $35 \pm 12$ & $0.73 \pm 0.6$ \\
Attendants & 29 & $8.07 \pm 1.6$ & $5.05 \pm 0.4$ & $119 \pm 42$ & $32 \pm 46$ & $39 \pm 15$ & $0.72 \pm 0.2$ \\
t, $P$-values & & $0.74,0.5$ & $0.11,0.9$ & $2.48,0.02$ & $0.9,0.7$ & $1.1,0.3$ & $0.06 ; 0.8$ \\
\hline
\end{tabular}


nutrition and during protein catabolism. The mean level of albumin in petrol-attendants was higher than in the normal controls, thus showing that the petrol attendants considered for this study were not having any of these conditions. Raised level of globulins in petrol attendants could be a result of raised immunoglobulin levels (as shown here by IgM and IgA) among other globulin fractions.

IgG comprise approximately $80 \%$ of the serum antibody. IgG is responsible for most antibacterial, antiviral and antitoxic activity. It is the only immunoglobulin capable of crossplacental transfer and therefore plays an important role in boost protection in the newborn. ${ }^{[10]}$ The level of IgG is increased in liver diseases and infections (e.g., malaria). Based on the insignificant reduction in the level of IgG in petrol attendants, it is likely that they do no have liver diseases; but further IgG decreases, which may be caused by chronic exposure to petrol, could result in reduced phagocytosis and cytotoxicity, thus explaining the susceptibility of chronically exposed petrol attendants to infection. IgA is the second most common immunoglobulin in human serum (after IgG) and is the predominant immunoglobulin found in mucosal secretion. Secretory IgA can neutralize viruses, bind toxins, agglutinate bacteria, prevent bacteria binding to mucosal epithelial cells and bind to various food antigens, thus preventing their entry into the general circulation. The role of serum IgA is unclear, but it was found to have antimicrobial activity. IgA deficiency is more frequent in adult subjects with chronic lung disease, recurrent sino-pulmonary infection, viral infections, autoimmune conditions, and gastrointestinal tract infection and disorders. ${ }^{[7,10]}$ It is possible that slightly raised $\operatorname{IgA}$ in petrol attendants is caused by stimulation of respiratory tracts by inhaled petrol fumes.

IgM is the most primitive and largest immunoglobulin of the five classes (IgG, IgA, IgM, IgD and IgE). It fixes complement most efficiently and for this reason, has an important function in complement-dependent bacteriolysis (especially of gramnegative organisms). The level of IgM is increased in liver diseases (primary biliary cirrhosis, early hepatitis) and infections (malaria, trypanosomiasis), thus raised level of IgM in petrol attendants could be related to malaria parasiteamia, which is predominant in Nigerians.

ALP is an enzyme in the cells lining the biliary ducts of the liver. If there is an obstruction in the bile duct, ALP levels in plasma will rise. ALP is also present in placental tissue and in growing children for bone remodeling. ${ }^{[8]}$ All the subjects considered for this study are adult males; therefore, significantly low levels of ALP in petrol attendants indicate absence of bile duct obstruction.

ALT is an enzyme present in hepatocytes (liver cells), and it leaks into blood when liver cells are damaged. ALT rises dramatically in acute liver damage (such as viral hepatitis and paracetamol overdose) and during liver inflammation. The similarities in the levels of ALT found in petroleum attendants and controls indicate normal liver function. AST is similar to ALT in that it is another enzyme associated with liver parenchymal cells. It is raised in acute liver damage and is also present in red cells and cardiac muscle. Since AST is not specific for the assessment of liver function, slightly raised AST in petrol attendants might be due to gradual lyses of red blood cells.

Bilirubin is essentially a waste product, found when RBC die and hemoglobin $(\mathrm{Hb})$ is broken down. $\mathrm{Hb}$ is broken down within the macrophages to heme and globin. The heme is further degraded to $\mathrm{Fe}^{2+}, \mathrm{CO}$ and bilirubin via the intermediate compound biliverdin. Since bilirubin is poorly soluble in water, it is carried to the liver bound to albumin. Bilirubin is made water-soluble in the liver by conjugation with uridine diphosphoglucuronic acid. As part of the bile, the soluble or 'conjugated' bilirubin passes through the common bile duct and is either temporarily stored in the gallbladder or passes right away into the gut. Some of the excreted bilirubin may be reabsorbed from the gut (entero-hepatic circulation). Bacteria in the intestines modify bilirubin to form stereobilinogen, causing the brown color of feces. The yellow color of urine is a result of urobilin (another breakdown product of bilirubin).

In adults, bilirubin is measured to diagnose and/or monitor liver diseases (cirrhosis hepatitis or gallstones). Jaundice results from high levels of bilirubin, and increases in bilirubin may be due to metabolic problems, obstruction of the bile duct, physical or chemical damage to liver or inherited abnormality. ${ }^{[11]}$ Similar levels of total bilirubin in petrol attendants and controls are an indication that no hemolysis or liver damage occurred in the petrol attendants. Since albumin binds bilirubin, slightly reduced levels of bilirubin may account for the slightly increased level of albumin in the petrol attendants.

Evidences suggest that albumin and bilirubin are secondary antioxidants, which trap newly formed free radicals before they can initiate chain reaction (propagation). This reaction may cause cell damage and further free radical formation. Petrol fume is known to contain reactive oxygen species $i^{[1,2]}$ this may be responsible for the consumption of bilirubin. A study on antioxidant status of petrol attendants is therefore advised.

\section{This present study shows that in petrol attendants:}

1. Only ALP is significantly different (reduced) out of all the liver functions (TP, albumin, AST, ALT, ALP, total bilirubin) assessed.

2. Only IgM is significantly altered (raised) out of all the 
immunoglobulin classes (IgG, IgA and IgM) determined.

At present, it may be concluded that liver functions are normal in Nigerian petrol attendants, and excess production of IgM is possible in cases of long-time exposure to petrol.

\section{REFERENCES}

1. Micyus NJ, McCurry JD, Seeley JV. Analysis of aromatic compounds in gasoline with flow-switching comprehensive two-dimensional gas chromatography. J Chromatogr A 2005;1086:115-21.

2. Lewne M, Nise G, Lind ML, Gustavsson P. Exposure to particles and nitrogen dioxide among taxi, bus lorry drivers. Int Arch Occup Environ Health 2006;79:220-6. Epub 2005 Nov 9.

3. Pranjic N, Mujagic H, Nurkic M, Karamehic J, Pavlovic S. Assessment of health effects in workers at gasoline station. Bosn J Basic Med Sci 2002;2:35-45.

4. Misiewicz A. Effect of air containing gasoline, wolfram, titanium, cobalt and vanadium on the phagocytic activity of leukocytes. Pol Tyg Lek 1980;35:1965-7.
5. Massad E, Saldiva PH, Saldiva CD, Caldeira MP, Cardoso LM, de Morais AM, et al. Toxicity of prolonged exposure to ethanol and gasoline autoengine exhaust gases. Environ Res 1986;40:479-86.

6. Yamamoto T, Wilson CB. Binding of anti-basement membrane antibody to alveolar basement membrane after intratracheal gasoline instillation in rabbits. Am J Pathol 1987;126:497-505.

7. Arinola OG, Salimonu LS. Humoral immunity in Nigerians with urinary schistosomiasis. West Afr J Med 1999;18:275-80.

8. Olaniyi JA, Arinola OG, Esogurah BC, Akibinu MO. Liver and renal functions in Nigerian sickle cell disease patients. Science Focus 2003;5:78-81.

9. Loganathan G, George R, Eapen CE, Mathai M, Jasper P, Seshadri L, et al. Liver function tests in normal pregnancy: A study from Southern India. Indian J Gastroenterol 2005;24:268-9

10. Salimonu LS, Immunoglobulins. In: Basic Immunology for Students of Medicine and Biology. $2^{\text {nd }}$ ed. (Salimonu LS, editor). College Press: Nigeria; 2004. p. 56-76.

11. Hanko E. Unbound bilirubin and risk assessment in the jaundiced newborn: Possibilities and limitations. Pediatrics 2006;117:526-7.

Source of Support: Nil, Conflict of Interest: None declared.

\section{Author Help: Online Submission of the Manuscripts}

Articles can be submitted online from http://www.journalonweb.com. For online submission articles should be prepared in two files (first page file and article file). Images should be submitted separately.

1) First Page File:

Prepare the title page, covering letter, acknowledgement, etc., using a word processor program. All information which can reveal your identity should be here. Use text/rtt/doc/pdf files. Do not zip the files.

2) Article file:

The main text of the article, beginning from Abstract till References (including tables) should be in this file. Do not include any information (such as acknowledgement, your names in page headers, etc.) in this file. Use text/rtf/doc/pdf files. Do not zip the files. Limit the file size to $400 \mathrm{~kb}$. Do not incorporate images in the file. If file size is large, graphs can be submitted as images separately without incorporating them in the article file to reduce the size of the file.

3) Images:

Submit good quality colour images. Each image should be less than $\mathbf{1 0 0} \mathbf{~ k b}$ in size. Size of the image can be reduced by decreasing the actual height and width of the images (keep up to about 3 inches) or by reducing the quality of image. All image formats (jpeg, tiff, gif, bmp, png, eps, etc.) are acceptable; jpeg is most suitable. The image quality should be good enough to judge the scientific value of the image. Always retain a good quality, high resolution image for print purpose. This high resolution image should be sent to the editorial office at the time of sending a revised article.

4) Legends:

Legends for the figures/images should be included at the end of the article file. 